\title{
Perspective/Discussion on "Quantum Mechanical Metric for Internal Cohesion in Cement Crystals" by C. C. Dharmawardhana, A. Misra and Wai-Yim Ching
}

\author{
Natt Makul (D)
}

Citation: Makul, N.

Perspective/Discussion on “Quantum Mechanical Metric for Internal Cohesion in Cement Crystals" by C. C. Dharmawardhana, A. Misra and Wai-Yim Ching. Crystals 2021, 11, 1450. https://doi.org/ $10.3390 /$ cryst 11121450

Received: 19 October 2021

Accepted: 19 November 2021

Published: 24 November 2021

Publisher's Note: MDPI stays neutral with regard to jurisdictional claims in published maps and institutional affiliations.

Copyright: (C) 2021 by the author. Licensee MDPI, Basel, Switzerland. This article is an open access article distributed under the terms and conditions of the Creative Commons Attribution (CC BY) license (https:// creativecommons.org/licenses/by/ $4.0 /)$.
Department of Civil Engineering Technology, Faculty of Industrial Technology, Phranakhon Rajabhat University, Bangkhen, Bangkok 10220, Thailand; natt@pnru.ac.th

Abstract: The single most important structural material, and the major Portland cement binding phase in application globally, is calcium silicate hydrate (C-S-H). The concentration has increasingly changed due to its atomic level comprehension because of the chemistry and complex structures of internal C-S-H cohesion in cement crystals at different lengths. This perspective aimed at describing on calcium-silicate-hydrates (C-S-H) structures with differing contents of $\mathrm{Ca} / \mathrm{Si}$ ratio based on the report entitled "Quantum mechanical metric for internal cohesion in cement crystals" published by C. C. Dharmawardhana, A. Misra and Wai-Yim Ching. Crystal structural and bond behaviors in synthesized C-S-H were also discussed. The investigator studied large subset electronic structures and bonding of the common C-S-H minerals. From each bonding type, the results and findings show a wide variety of contributions, particularly hydrogen bonding, that allow critical analyses of spectroscopic measurement and constructions of practical C-S-H models. The investigator found that the perfect overall measurement for examining crystal cohesions of the complex substances is the total bond density (TBOD), which needs to be substituted for traditional metrics such as calcium to silicon ratios. In comparison to Tobermorite and Jennite, hardly known orthorhombic phased Suolunites were revealed to have greater cohesion and total order distribution density than those of the hydrated Portland cement backbone. The findings of the perspective showed that utilizing quantum mechanical metrics, the total bond orders and total bond order distributions are the most vital criteria for assessing the crystalline cohesions in C-S-H crystals. These metrics encompass effects of both interatomic interactions and geometric elements. Thus, the total bond order distribution and bond order offer comprehensive and in-depth measures for the overall behaviors of these diverse groups of substances. The total bond order distributions must clearly be substituted for the conventional and longstanding $\mathrm{Ca} / \mathrm{Si}$ ratios applied in categorizing the cement substances. The inconspicuous Suolunite crystals were found to have the greatest total bond order distributions and the perfect bonding characteristics, compositions, and structures for cement hydrates.

Keywords: quantum cement chemistry; calcium-silicate-hydrate (C-S-H); cohesion

\section{Introduction}

Characteristics of inter-atomic bonding and electronic structures are primary to the detailed comprehension of C-S-H properties and the atomic-scale structures that are fused as products of Portland cement hydration [1]. This perspective aimed at describing calciumsilicate-hydrates (C-S-H) structures with differing $\mathrm{Ca} / \mathrm{Si}$ ratios. Crystal structural and bond behaviors in synthesized C-S-H were also discussed [1].

In the atomic structure-property relationship, interest has emerged because of the progressively important economic, ecological, and social impacts of the generation and application of international Portland cements, which presently stand at two billion metric tons.

Based on a range of high-resolution microscopic and spectroscopic methods, current experimental results and findings show fully disordered or poorly crystalline atomic structures of the hydrate in hardened cement pastes [2]. Various structural models have 
been recommended based on these experimental findings, either via hypothetical modeling or binary solution utilizing crystal types of Tobermorite and Jennite as beginning structures. The efforts have led to a broad variety of models for C-S-H that are either based on limited atomistic simulations or solution theories applying classical molecular dynamics (MD) [3]. In these efforts, a major missing ingredient is the comprehension of bonding properties of more disordered C-S-H and the crystalline C-S-H. To represent anhydrate crystals and calcium silicate hydrate, the investigator follows the cement chemistry notations of CS and C-S-H for clarity and brevity $[4,5]$. The researcher used C-S-H to symbolize calcium silicate hydrates' more general structures found in hardened cement pastes.

Phases of crystalline C-S-H vary to highly ordered crystalline from almost amorphous phases. Various doubts persist about the structures and compositions for C-S-H higher crystallinity phases because of the difficulty related to isolations of pure phases and their differing crystallinity level [6,7]. In addition, information relating to quantitative bonding, particularly hydrogen bonds (HBs), is inaccessible by experimental methods without the help of strong atomistic models for correct interpretations, because the complexities of $\mathrm{C}-\mathrm{S}-\mathrm{H}$ structures result in the famous chicken-eggs challenge. With well-documented crystal structures, it is of great significance to assess an extensive range of crystalline C-S-H stages in regarding this crucial disparity in knowledge. Such investigations offer comprehensive insights into the differences in bonding properties regarding the structures and compositions of the substances [8,9]. The C-S-H atomistic frameworks recommended in the studies shall continue being hypothetical without this information.

Regarding the position of ' $\mathrm{H}$ ', the uncertainties were previously explained in a study of four crystalline C-S-H crystals [10]. HBs play vital roles in the behaviors of these substances because they have an important presence in C-S-H. Generally, these facts have been acknowledged but rarely quantitatively researched. In the absence of advanced structures of these stages, the bonding data cannot clearly be identified purely from experimental information. In this case, the investigator took genomic approaches of materials and hypothetically examined an extensive variety of C-S-H crystals utilizing the correct first standard techniques [11,12]. The researcher selected fifteen crystals from the list of thirty crystalline phases in the 2008 evaluation journal by Richardson with clearly-documented structural data, and their four potential anhydrous Portlandites and precursors [13]. Of these crystalline phases, the investigator started with completely optimized atomic structures. To tackle the partial occupancy issues, the investigator used supercell approaches in some crystals at specific sites [14]. Then, the refined structures of electronic structures were computed. Through calculations of overlapping populations (bond order), the investigator quantitatively assessed the bonding properties of these crystals. Following the modified Strunz classifications of minerals, the investigator analyzed the data according to the polymerization level of the silicate chain in the crystals [15,16]. The results acquired from crystalline stages can assist in the interpretations of experimental spectroscopic metrics, resulting in realistic models that are reliable at both atomistic-scale and electronic-scale performances for the C-S-H phased in synthesized Portland cements.

\section{Crystal Structural Classifications and Relaxations}

An extensive review by Richardson [13] includes a comprehensive list of thirty C-S-H crystals. Taylor et al. [17] categorized the thirty C-S-H crystal phases into six categories. By considering the polymerization of the silica chains, the C-S-H crystals nevertheless can be more correctly categorized in accordance with the Strunz classifications [18]. Moreover, the silica chain polymerization notions have the effects on the complex hydration process products and biological degradations or carbonation that take place in Portland cement pastes $[19,20]$. It has been speculated that cement paste maturations chiefly involve improving polymerizations of isolated silicon tetrahedrons to pentamers, dimers, and trimmers, ultimately creating three-dimensional silicate frameworks [21].

Based on the well-documented atomic positions utilized in this research, Table 1 lists twenty crystal phases categorized into four classifications: iono-silicates, soro-silicates, 
nesosubsilicates, and clinkers and hydroxide phases [22]. In Table 1, each classification is organized in increasing order of Ca/Si ratio. Group (a) includes Portlandites (a.3) and clinker phases (a.1 and a.2). Portlandites are part of this classification because they form the cement hydration basis. The investigator used the Strunz schemes [18] to group the remaining crystals. At each polymerization stage, the silicate units are illustrated by Qn in this scheme, in which the silicon tetrahedrons are linked with $\mathrm{n}$ of other silicate tetrahedrons $[19,23]$. For example, Q0 denotes isolated silicate tetrahedrons not linked with any other silicate. Group (b) consists of the nesosubsilicates with isolated groups $\left(\mathrm{SiO}_{4}\right)$. The lowest polymerization degree is possessed by the C-S-H phases. In the next polymerization stage, the soro-silicates with $\left[\mathrm{Si}_{2} \mathrm{O}_{7}\right]$ groups are placed in class (c). The $\mathrm{Si}_{2} \mathrm{O}_{7}$ is linked with two isolated tetrahedrals to form the pyro-groups through one Bridging-O. Therefore, all Si tetrahedrals are Q1. The Si tetrahedral is connected through non-bridging $\mathrm{O}$ to 6,7 , or 8 fold-linked calcium atoms [20]. The mixtures of finite triple chains Q2 and isolated tetrahedral (Q0) are special cases of structures of soro-silicates in which the Si tetrahedrals are linked with six and eight fold-linked atoms bonded to calcium atoms. The inosilicates are in group (d). Varying to 1.5 in Jennite (d.8) from 0.50 in Nekoite (d.1), this comprises structures with a broad range of calcium to silicon ratios and infinitely long chains. In this group, the phases can be subcategorized into double chains (1/3 Q3 and $2 / 3$ Q2) and single chains (all tetrahedrals are Q2) according to the polymerization degree [24,25]. From each group, the representative crystals are shown in Figure 1. For group (a), these are Alites (a.2); for group (b), they are Afwillites (b.1); for group c they are Kilichoanites (c.3) and Suolunites (c.2); for group (d), they are Anomalous T11 A (d.2) and Forshgites (d.7). In the Supporting Information (SI), similar images of all twenty crystals are shown as Figure 1.

Table 1. Chemical characteristics of (a) clinkers/hydroxide phases, (b) nesosubsilicates, (c) soro-silicates and (d) inosilicates [26].

\begin{tabular}{|c|c|c|c|c|c|c|}
\hline \multicolumn{2}{|c|}{ Mineral Name } & $\mathrm{Sy}^{[1]}: \mathrm{sg}^{[2]}$ & Chemical Formulas & $\mathrm{Ca} / \mathrm{Si}$ & $\rho(g / c c)$ & Eg \\
\hline \multicolumn{7}{|c|}{ (a) Clinkers/Hydroxide stages } \\
\hline a.1 & Belites & $\mathrm{O}: P 121 / n 1$ & $2(\mathrm{CaO}) \mathrm{SiO}_{2}$ & 2.00 & 3.316 & 4.65 \\
\hline a. 2 & Alite & M: P-1 & $3(\mathrm{CaO}) \mathrm{SiO}_{2}$ & 3.00 & 3.084 & 3.68 \\
\hline a.3 & Portlandites & $\mathrm{M}: P-3 m 1$ & $\mathrm{Ca}(\mathrm{OH})_{2}$ & Inf & 2.668 & 3.50 \\
\hline \multicolumn{7}{|c|}{ (b) Nesosubsilicates } \\
\hline b.1 & Afwillite & M: P1 & $\mathrm{Ca}_{3}\left(\mathrm{SiO}_{3} \mathrm{OH}\right)_{2} \cdot 2 \mathrm{H}_{2} \mathrm{O}$ & 1.50 & 2.590 & 4.26 \\
\hline b. 2 & $\alpha-\mathrm{C}_{2} \mathrm{SH}$ & $\mathrm{O}: P 2_{1} / b 2_{1} / c 2_{1} / a$ & $\mathrm{Ca}_{2}\left(\mathrm{HSiO}_{4}\right)(\mathrm{OH})$ & 2.00 & 2.693 & 4.37 \\
\hline b. 3 & Dellaite & Tc: P-1 & $\mathrm{Ca}_{6}\left(\mathrm{Si}_{2} \mathrm{O}_{7}\right)\left(\mathrm{SiO}_{4}\right)(\mathrm{OH})_{2}$ & 2.00 & 2.929 & 4.12 \\
\hline b.4 & Ca Chondrodites & M: $P 1122_{1} / b$ & $\mathrm{Ca}_{5}\left[\mathrm{SiO}_{4}\right]_{2}(\mathrm{OH})_{2}$ & 2.50 & 2.828 & 4.24 \\
\hline \multicolumn{7}{|c|}{ (c) Sorosilicate } \\
\hline c. 1 & Rosenhahnites & Tc: P-1 & $\mathrm{Ca}_{3} \mathrm{Si}_{3} \mathrm{O}_{8}(\mathrm{OH})_{2}$ & 1.00 & 2.874 & 4.49 \\
\hline c. 2 & Suolunites & $\mathrm{O}: F d 2 d$ & $\mathrm{Ca}_{2}\left[\mathrm{Si}_{2} \mathrm{O}_{5}(\mathrm{OH})_{2}\right] \mathrm{H}_{2} \mathrm{O}$ & 1.00 & 2.649 & 4.87 \\
\hline c. 3 & Kilchoanites & $\mathrm{O}: \mathrm{I} 2 \mathrm{~cm}$ & $\mathrm{Ca}_{6}\left(\mathrm{SiO}_{4}\right)\left(\mathrm{Si}_{3} \mathrm{O}_{10}\right)$ & 1.50 & 2.937 & 4.40 \\
\hline c. 4 & Killalaites & M: $P 121 / m 1$ & $\mathrm{Ca}_{6.4}\left(\mathrm{H}_{\mathrm{O} .6} \mathrm{Si}_{2} \mathrm{O}_{7}\right)_{2}(\mathrm{OH})_{2}$ & 1.60 & 2.838 & 3.85 \\
\hline c.5 & Jaffeites & Tg: $P 3$ & $\mathrm{Ca}_{6}\left[\mathrm{Si}_{2} \mathrm{O}_{7}\right](\mathrm{OH})_{6}$ & 3.00 & 2.595 & 3.92 \\
\hline \multicolumn{7}{|c|}{ (d) Inosilicates } \\
\hline d.1 & Nekoite & Tc: P1 & $\mathrm{Ca}_{3} \mathrm{Si}_{6} \mathrm{O}_{15} \cdot 7 \mathrm{H}_{2} \mathrm{O}$ & 0.50 & 2.204 & 4.29 \\
\hline d. 2 & T11 Å & $\mathrm{M}: B 11 \mathrm{~m}$ & $\mathrm{Ca}_{4} \mathrm{Si}_{6} \mathrm{O}_{15}(\mathrm{OH})_{2} \cdot 5 \mathrm{H}_{2} \mathrm{O}$ & 0.67 & 2.396 & 4.15 \\
\hline d.3 & T14 Å & M: B $11 b$ & $\mathrm{Ca}_{5} \mathrm{Si}_{6} \mathrm{O}_{16}(\mathrm{OH})_{2} \cdot 7 \mathrm{H}_{2} \mathrm{O}$ & 0.83 & 2.187 & 4.04 \\
\hline d. 4 & T9 Å & Tc: C1 & $\mathrm{Ca}_{5} \mathrm{Si}_{6} \mathrm{O}_{17} 5 \mathrm{H}_{2} \mathrm{O}$ & 0.83 & 2.579 & 4.57 \\
\hline d.5 & Wollastonites & Tc: P-1 & $\mathrm{Ca}_{3} \mathrm{Si}_{3} \mathrm{O}_{9}$ & 1.00 & 2.899 & 4.62 \\
\hline d. 6 & Xonotlites & Tc: A-1 & $\mathrm{Ca}_{6} \mathrm{Si}_{6} \mathrm{O}_{17}(\mathrm{OH})_{2}$ & 1.00 & 2.655 & 4.27 \\
\hline d.7 & Foshagites & Tc: P-1 & $\mathrm{Ca}_{4}\left(\mathrm{Si}_{3} \mathrm{O}_{9}\right)(\mathrm{OH})_{2}$ & 1.33 & 2.713 & 4.41 \\
\hline d. 8 & Jennites & Tc: P-1 & $\mathrm{Ca}_{9} \mathrm{Si}_{6} \mathrm{O}_{18}(\mathrm{OH})_{6} \cdot 8 \mathrm{H}_{2} \mathrm{O}$ & 1.50 & 2.310 & 4.43 \\
\hline
\end{tabular}

Remarks: ${ }^{[1]}$ Sy $=$ crystal symmetries. ${ }^{[2]} \mathrm{Sg}=$ space group symmetries. 
(a.2) Alite

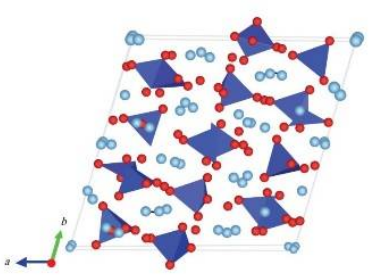

(c.3) Kilchoanite (b.1) Afwillite

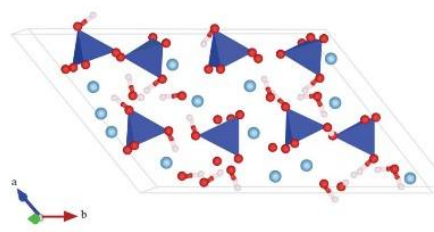

(d.2) Anomalous T11 §
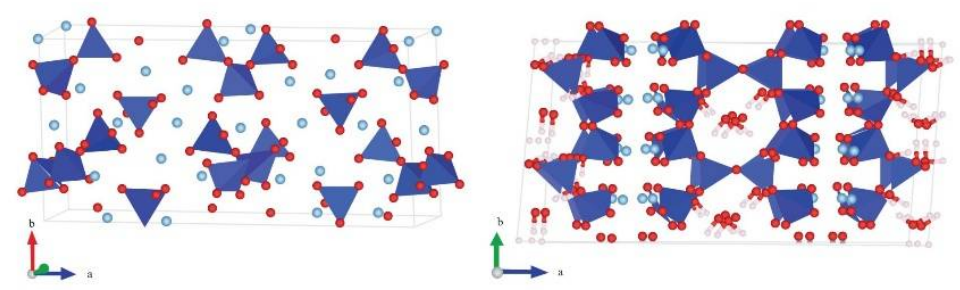

(c.2) Suolunite

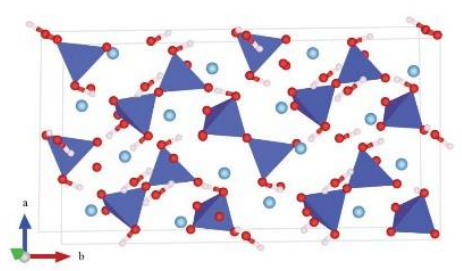

(d.7) Foshagite

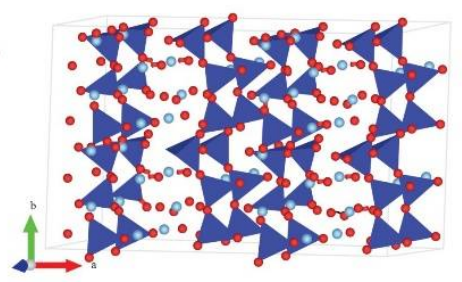

Figure 1. Crystals structures of C-S-H and C-S crystal: (a.2) Alites; (b.1) Afwillites; (c.2) Suolunites; (c.3) Kilchoanites; (d.2) Anomalous T11 ̊; (d.7) Foshagites [27].

The researcher utilized the Vienna ab initio simulation package (VASP) for the C-S-H crystal structural relaxations $[14,28]$. The technical information is concisely explained as follows: (1) An adequately large number of k-point meshes varying from 2.0 to $85.0 \mathrm{k}$ points were utilized relying on the real sizes and structures of crystals; (2) high energy cutoffs of $500 \mathrm{eV}$ were adopted; (3) for the ionic relaxations, the criteria of force convergence were set at $1025 \mathrm{eV} / \AA$; and (4) with the generalized gradient approximations (GGAs), the PAW-PBE potentials were used $[29,30]$.

\section{C-S-H Electronic Structures}

Inaccuracies exist together with some missing information, although the crystal atomic structures are generally available, as shown in the Table 1 [31]. To merge with the chemical formulas where appropriate, Figure 1 and Section 1 in the Supplementary Materials provide additional data on the corrected and completely relaxed structures. A summary of computed electronic band gaps, calcium/silicon ratios, theoretical density, chemical formulas, and crystal symmetry are given in table one. Of the twenty crystals researched, five are both hydroxyl and isolated water groups, two have purely isolated water molecules, four are anhydrate phases, and the remaining nine have only hydroxyl classes $[25,26]$. Hydroxyl classes are majorly bonded to $\mathrm{Si}(\mathrm{Si}-\mathrm{OH})$ in $\mathrm{C}-\mathrm{S}-\mathrm{H}$. However, they can also be bonded to $\mathrm{Ca}(\mathrm{Ca}-\mathrm{OH})$ in some cases (d.7, d.6, c.5, c.4, c.2, b.3, b.2, and b.1). Figure 2 displays the computed band structures for the twenty crystals. The energy zero is set at the valance band (VB) or the highest occupied state [26]. All crystals portray a flat top of the valance band except a.3, and have larger band disparities varying from 3.50 to $4.87 \mathrm{eVs}$, as anticipated. Of all crystals, the conduction band (CB) bottoms have a large curvature, showing insignificant electron effective masses. Analyses of the partial densities of state (PDO) indicate that the valance band upper parts are from the O-2P orbital of the non-water $\mathrm{O}$ and the valance band lower part is from the O-2s orbital [6,27]. The lower conduction bands originate majorly from Ca-3d orbitals. 

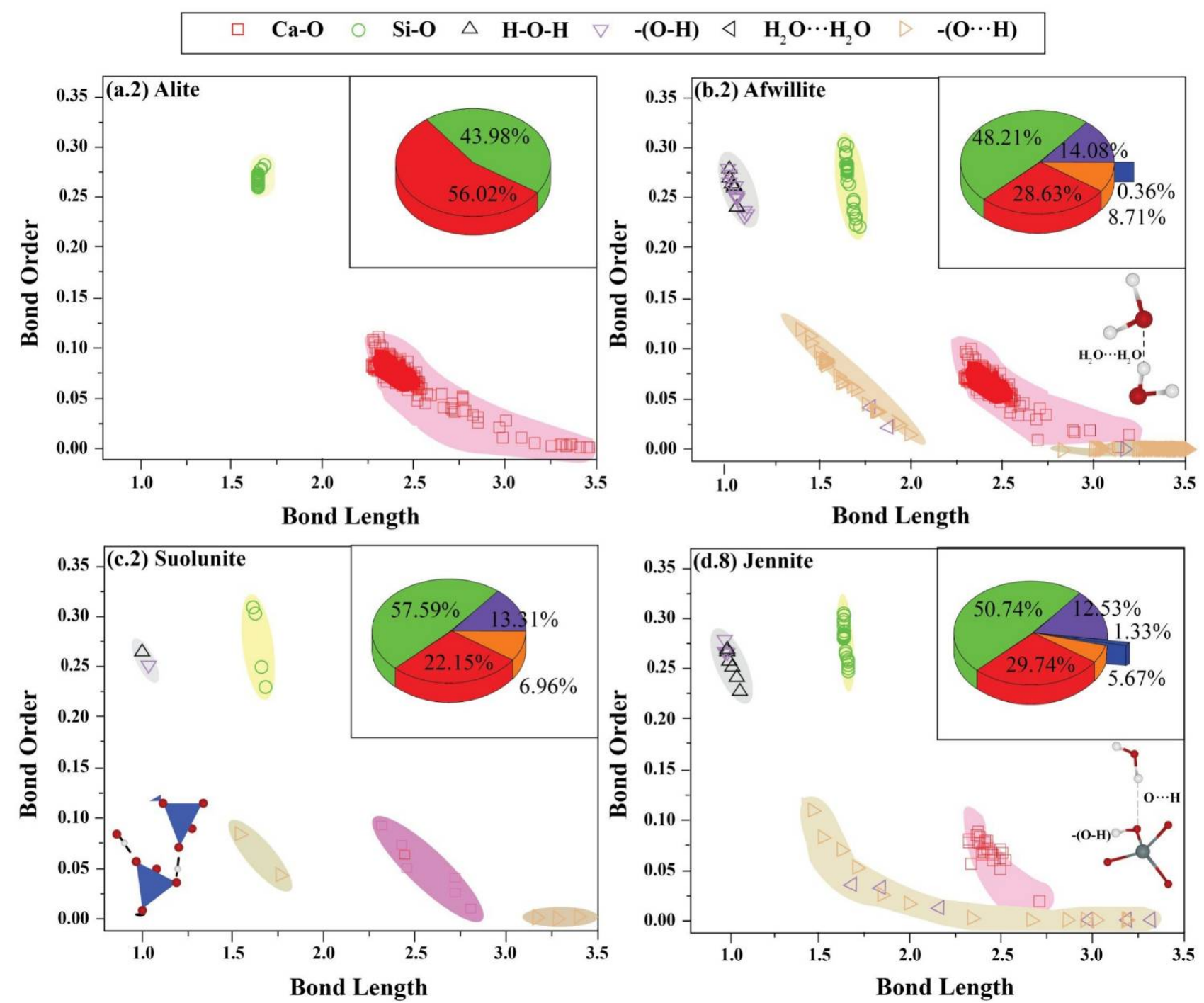

Figure 2. Distributions of bond orders and bond length for (a.2) Allites; (b.2) Alwillites; (c.2) Suolunites; and (d.8) Jennites. Cryptograms of bonds include "-" for covalent bonds, "..." for HBs. In the inserts, the pie charts show percentages of different bonding types: blue hydrogen bonds between water molecules; orange, other hydrogen bonds (HBs); violet, covalent-(O-H); green, Si-O; and red, Ca-O. Different hydrogen bond types are shown by lower insets [6].

There are also significant contributions from the Si-3d orbital to the upper parts of the valence band [6,32]. Based on correctly relaxed structures, high quality band structures are crucial in examining the electronic structures because experimentally measured structures are often not adequately accurate. For a hydrated crystal with a water molecule, this is particularly true. In earlier works, discrepancies with the experimentally apportioned " $\mathrm{H}$ " position have been pointed out. The percent deviations and the VASP relaxed crystals' parameters from experimentally recorded values are showed in Table $2[33,34]$. Table S1 in the Supplementary Materials gives the parameters of experimental crystals. In general, the parameters of relaxed crystals range from $1 \%$ to $2 \%$ in comparison with the recorded experimental figures. However, they can be as high as $24.10 \%$ in some circumstances, such as b.1 and b.4 [8]. The greatest deviations are in the Awfillite (b.1) crystal structure angle c. These are greatly hydrated phases and the investigator found substantial deviations in the hydrogen position from the recorded structures. This deviation is bigger than those often present in other inorganic crystals. In the values reported at different times by diverse groups applying multiple techniques for some of the C-S-H minerals, there are obviously large uncertainties $[35,36]$. Based on density functional theory, accurate 
theoretical calculations can thus offer the required consistencies for crystal structures of C-S-H, based on which consistent characteristics can be analyzed.

Table 2. Crystal parameters of (a) clinker/hydroxide phases, (b) nesosubsilicates, (c) soro-silicates and (d) inosilicates [26] (\% error from experiments).

\begin{tabular}{lllllll}
\hline & \multicolumn{1}{c}{$\mathbf{a}(\mathbf{\AA})$} & \multicolumn{1}{c}{$\mathbf{b}(\mathbf{\AA})$} & \multicolumn{1}{c}{$\mathbf{c}(\AA)$} & \multicolumn{1}{c}{$\alpha^{\circ}$} & \multicolumn{1}{c}{$\boldsymbol{\beta}^{\circ}$} & \multicolumn{1}{c}{$\gamma^{\circ}$} \\
\hline a.1 & $5.565(-1.1)$ & $6.8(-0.6)$ & $9.363(-0.4)$ & $90(0)$ & $94.70(-0.6)$ & $90(0)$ \\
a.2 & $11.733(-0.8)$ & $14.298(-0.9)$ & $13.743(-0.7)$ & $104.80(0.2)$ & $94.36(0.3)$ & $90.11(0)$ \\
a.3 & $3.614(-0.6)$ & $3.614(-0.6)$ & $4.958(-1.1)$ & $90.18(-0.2)$ & $89.82(0.2)$ & $120.025(0)$ \\
\hline b.1 & $16.57(-1.5)$ & $5.719(-1.4)$ & $11.764(-0.7)$ & $87.59(2.8)$ & $127.06(-0.5)$ & $93.65(-4.1)$ \\
b.2 & $9.535(-0.5)$ & $9.228(-0.5)$ & $10.777(-1)$ & $90(9)$ & $90(0)$ & $90(0)$ \\
b.3 & $6.888(-0.5)$ & $7.028(-1.1)$ & $12.952(-0.4)$ & $90.10(0.7)$ & $97.29(0)$ & $98.28(0)$ \\
b.4 & $8.956(-0.4)$ & $11.556(-0.9)$ & $5.111(-0.7)$ & $90.56(-0.6)$ & $89.28(0.8)$ & $108.71(-0.4)$ \\
\hline c.1 & $7.052(-1.4)$ & $9.548(-0.7)$ & $6.888(-1)$ & $108.78(-0.1)$ & $95.73(-0.9)$ & $95.34(0.6)$ \\
c.2 & $19.988(-1.1)$ & $6.036(-0.8)$ & $11.239(-1.1)$ & $90(0)$ & $90(0)$ & $90(0)$ \\
c.3 & $11.527(-0.9)$ & $5.13(-0.8)$ & $22.204(-1.2)$ & $90(0)$ & $90(0)$ & $90(0)$ \\
c.4 & $20.638(-0.8)$ & $15.607(-0.9)$ & $6.898(-0.9)$ & $90(0)$ & $97.17(0.5)$ & $89.87(0.1)$ \\
c.5 & $10.085(-0.5)$ & $10.084(-0.5)$ & $7.538(-0.5)$ & $90(0)$ & $90(0)$ & $120(0)$ \\
\hline d.1 & $7.665(-1)$ & $9.797(0)$ & $7.418(-1.1)$ & $110.94(0.7)$ & $103.59(-0.1)$ & $86.69(-0.2)$ \\
d.2 & $6.736(0)$ & $7.451(-0.9)$ & $22.73(-1.1)$ & $89.63(0.4)$ & $90.42(-0.5)$ & $122.22(0.8)$ \\
d.3 & $6.706(0.4)$ & $7.416(0.1)$ & $28.589(-2.1)$ & $90.70(-0.8)$ & $92.45(-2.7)$ & $122.65(0.5)$ \\
d.4 & $11.414(-1.2)$ & $7.416(-1)$ & $11.48(-0.1)$ & $98.36(0.8)$ & $97.05(0.1)$ & $90.23(-0.2)$ \\
d.5 & $8.009(-0.9)$ & $7.381(-0.8)$ & $7.139(-1)$ & $90.08(-0.1)$ & $95.53(-0.2)$ & $103.44(0)$ \\
d.6 & $8.786(-0.8)$ & $7.422(-0.8)$ & $14.193(-1.2)$ & $89.95(0)$ & $90.66(-0.3)$ & $102.25(-0.1)$ \\
d.7 & $10.423(-1)$ & $7.367(-0.1)$ & $7.159(-1.7)$ & $90.07(-0.1)$ & $106.48(-0.1)$ & $89.98(0)$ \\
d.8 & $10.732(-1.5)$ & $7.349(-1.2)$ & $10.784(1.3)$ & $103.22(-1.9)$ & $94.78(2.3)$ & $110.24(-0.5)$ \\
\hline
\end{tabular}

\section{Calculations of Bond Orders in C-S-H}

On the basis of the VASP-relaxed crystal structures, the researcher utilized the orthogonalized linear combinations of atomic orbitals (OLCAOs) for bonding analyses and electronic structures $[25,37]$. Using Mullikan population analyses, values of bond order for every crystal were computed. In the SI, more comprehensive descriptions of the bond order computations are included. The total bond order dimensions were acquired as aggregate total bond orders from all special pairs divided by the volumes of cells [38]. The bond order percentage contributions do not include the water molecule covenant $\mathrm{O}-\mathrm{H}$ bond because it does not directly contribute to the crystal internal cohesions.

The bond orders (BOs) between pairs of atoms represent the bond strength and stiffness quantitative measures [24]. In the C-S-H crystals, the bond order is important in disclosing the internal cohesion origin. Utilizing the initial principles of orthogonalized linear bonds of atomic orbitals (OLCAO) methods, the researcher obtained the BO figures between each pair of atoms in the crystals. For four representative C-S-H from every class (a. Alites, b. Afwillites, c. Suolunites and d. Jennites), the distributions of bond length and bond order were obtained. In each crystal, $\left[-(\mathrm{O} \ldots \mathrm{H}), \mathrm{H}_{2} \mathrm{O} \ldots \mathrm{H}_{2} \mathrm{O},-(\mathrm{O}-\mathrm{H}), \mathrm{H}-\mathrm{O}-\mathrm{H}, \mathrm{Si}-\mathrm{O}\right.$, and $\mathrm{Ca}-\mathrm{O}]$, different bond types are as illustrated [25]. There are two $\mathrm{OH}$ bond types as evident. They have weak HBs bonds and strong covalent bonds. In addition, there are two covalent $\mathrm{O}-\mathrm{H}$ bond types: those in hydroxyl ions $-(\mathrm{O}-\mathrm{H})$ that bond to calcium ions $(\mathrm{Ca}-\mathrm{OH})$ and silicates $(\mathrm{Si}-\mathrm{OH})$, and the one contained by $\mathrm{H}_{2} \mathrm{O}$ molecules $(\mathrm{HO}-\mathrm{H})$ that do not result in internal cohesions [27]. Moreover, the HBs have two classifications: HBs among all other $\mathrm{HBs}$ types that are not completely amid two isolated $\mathrm{H}_{2} \mathrm{O}$ molecules, and those between molecules of water $\left(\mathrm{H}_{2} \mathrm{O} \ldots \mathrm{H}_{2} \mathrm{O}\right)$ as indicated in the insets of Figure 2 for b.1; for example, the HBs such as $\mathrm{H}_{2}(\mathrm{O} \ldots \mathrm{H}) \mathrm{O}-\mathrm{Si}$ and $\mathrm{Si}-(\mathrm{O} \ldots \mathrm{H}) \mathrm{O}-\mathrm{Si}$, which are specifically important, are indicated as insets of Figure 2 for d.8 and c.2, respectively [26]. The researcher defined the total bond order densities (TBODs) to be the TBO standardized by the crystal volumes and total bond orders (TBOs) to be the total of individual bond order figures. 
In Figure 2, the pie charts give the proportion contributions from diverse bond types to the total bond order [27]. In computing the percentage contribution, it is worth noting that the researcher ignored the bond order contributions from covalent $\mathrm{O}-\mathrm{H}$ bonds from water molecules because they do not contribute directly to the overall cohesions. The general representative pictures of relative strengths and distributions of diverse bond species in C-S-H crystals are given in Figure 2 [6]. Within a fairly narrow variety of Si-O bond lengths, the almost continuous and broad distributions of $\mathrm{Si}-\mathrm{O}$ bond order values clearly show that the strength and stiffness of the bonds, rather than the bond lengths, are the chief reasons why the spectral characteristics related to $\mathrm{Si}-\mathrm{O}$ bonds usually seem as wide peaks. Moreover, it is noticeable that HB covers broad ranges of bond lengths and bond orders in these materials and makes significant contributions to the total bond order. In experimental spectroscopic methods, the HB effects have been broadly speculated about but never precisely discussed [32,33]. In each group, the researcher describes the distribution of the bond order for crystals in the following, illustrating the complex pictures of diverse bond order distributions to the crystal cohesions and regarding their structural characterizations.

\section{Bond Order Distributions for Every Class}

The plots of bond order versus bond length and the percentage distributions from diverse bond types to the total bond orders for all twenty crystals are displayed in Figure 3. Alites (a.2) and Belite (a.1) have only Q0 silicate in group (a) [34]. With the bond length positioned at $1.65 \AA$, the bonds of $\mathrm{Si}-\mathrm{O}$ have narrow bond order distributions positioned at 0.27. Varying from 2.25 to $3.50 \AA$ and 0.02 to 0.10 , respectively, the much weaker calciumoxygen bond exhibits a larger bond length and bond order dispersions [35]. Whereas the Ca-O bond in Alites shows some distributions of 2.27 to $2.55 \AA$, in Belite the calcium-oxygen bond has virtually evenly distributed bond orders and bond lengths. The dispersions of bond order and bond length clearly describe why a noticeably sharp and strong siliconoxygen peak dominates the minerals' experimental vibrational analysis, in contrast with the weaker and broad peak related to calcium-oxygen bonds [6,27]. In Portlandites (a.3), it is worth noting that with a bond length of $2.381 \AA$, the 0.2230 bond order for calciumoxygen bonds is much higher than the calcium-oxygen bond in all the C-S-H crystals and the above C-S crystals.

The crystals of group (b) have HBs, the Q0 silicate, and covalent $\mathrm{OH}$ bonds [32]. Only Afwillites have a water molecule in this group. Although they have a well-defined and narrow range of bond lengths, these crystals have widely distributed bond orders of $\mathrm{Si}-\mathrm{O}$. Although the higher bond orders with Si-O bonds are within the tetrahedral units, the lower $\mathrm{Si}-\mathrm{O}$ bond orders are basically related to the $\mathrm{Si}-\mathrm{OH}$ (hydroxyls) bonds [39]. In group (b) crystals, the $\mathrm{Ca}-\mathrm{O}$ bond orders are significantly smaller and indicate narrow dispersions over a broad variety of bond lengths. in addition, $\mathrm{HBs}$ and $\mathrm{O}-\mathrm{H}$ covalent bonds show a broad variety of bond lengths and bond orders, as anticipated. In this group, the contribution from $\mathrm{HBs}, \mathrm{Ca}-\mathrm{O}$, and $\mathrm{O}-\mathrm{H}$ bonds to the total bond order are approximately $50 \%$ or more for all the crystals. For instance, the contributions to the total bond order in Afwillites (b1) are as follows: O ... H (8.7\%), O-H (14.10\%), Ca-O (28.60\%), and Si$\mathrm{O}(48.20 \%)$ [40]. The silicate tetrahedral units $\left[\mathrm{HSiO}_{4}\right]$ are bonded to the covalent $\mathrm{O}-\mathrm{H}$ bonds with significant bond order values and $\mathrm{HB}$ whole bond lengths that differ within 1.380-1.980 $\AA$. In Afwillites, the $-\mathrm{O}$. . . H contributions are the greatest $(8.71 \%)$. In the analysis of the Afwillite IR spectra, Rastsvetaeva et al. allocated the typical vibrational modes of the zundel cations $\left(\mathrm{H}_{5} \mathrm{O}_{2} 1\right)$ or $\left(\mathrm{H}_{2}-\mathrm{O} \ldots \mathrm{H} \ldots \mathrm{OH}_{2}\right)$ [33]. Nevertheless, the researcher did not observe these zundel cation structures in the bond order analyses. Rather, as indicated in Figure 1 (b.1), the researcher found two HB bonding molecules of water with close proximities on either sides of $\mathrm{CaO}$ layers (parallel to b-c planes). The IR spectra interpretations clearly may have massively gained from bond order computations and relaxed structures [36]. On the contrary, the $\mathrm{HB}$ associated with $\mathrm{Si}-\mathrm{OH}$ is comparatively strong (bond order $=0.066$ ) in comparison with those associated with the $\mathrm{Ca}-\mathrm{OH}$ (bond 
order $=0.014$ ) for $\mathrm{a}_{-} \mathrm{C}_{2} \mathrm{SH}(\mathrm{b} .2)$, which has both $\mathrm{Ca}-\mathrm{OH}$ and $\mathrm{Si}-\mathrm{OH}$. In $\mathrm{a}-\mathrm{C}_{2} \mathrm{SH}(\mathrm{b} .2)$, the strong $\mathrm{HBs}$ can be associated with the fact that these crystals are created under conditions of higher hydrothermal temperatures and are stable even at extreme temperatures [21]. Ca-Chondodites (b.4) and Dellaites (b.3), the other two crystals in group (b), indicate insignificant contributions from $\mathrm{HB}$ due to the large $\mathrm{O} \ldots \mathrm{H}$ separation [40]. The $\mathrm{O}-\mathrm{H}$ covalent bonds, and the $\mathrm{Si}-\mathrm{O}$ and $\mathrm{Ca}-\mathrm{O}$ bonds, make major contributions to the total bond orders in these two crystals.

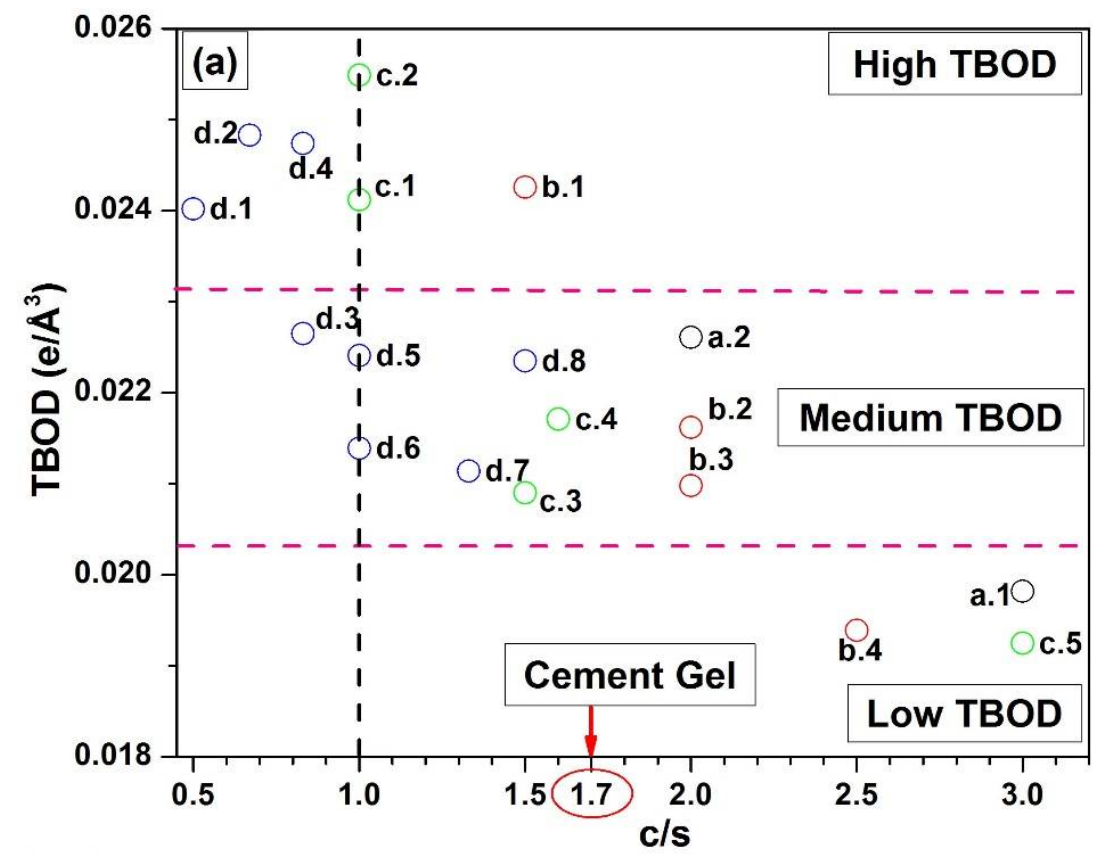

(b)

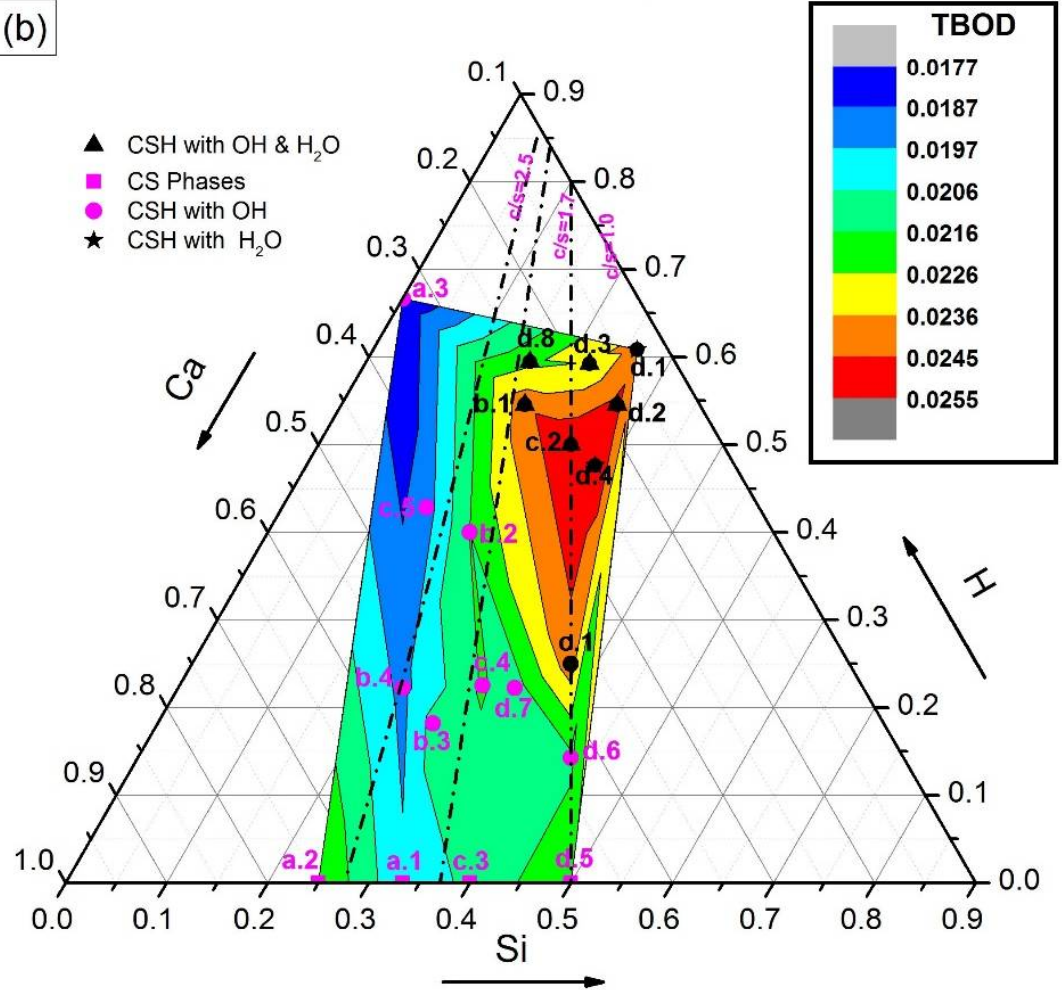

Figure 3. (a) TBOD and C/S ratios and (b) distribution maps of TBOD and the compositions of Ca:Si:H. The color bars label the TBOD values [6].

In group (c), crystals have even broader distributions than group (b) of bond order values of Si-O, which vary from 0.18 to $0.35[34,41]$. Whereas contributions from HBs are 
relatively smaller, the contributions from Si-O bonds to total bond orders are generally higher than those in group (b). With two silicate chain types (Q2 and Q0) co-existing, Kilichoanites (c.3) in this group are naturally occurring anhydrous crystals [35]. Similar to group (b) and group (a), the O-H covalent bonds are distributed in very narrow ranges for crystals other than Kilichoanites (c.3). As in group (b), the HBs follow similar ranges of 1.5 to $1.80 \AA$. The group crystals portray broad variations in bonding and structural characteristics even though they share the Strunz classifications [18]. For instance, the Killalaites (c.4) are non-stoichiometric and complex crystals with partial occupancies. They consist of chains of Q1 silicates through O corner sharing with $124.8 \mathrm{u}$ SiO-Si angles. These crystals contain both units of $\mathrm{Ca}-\mathrm{OH}$ and $\mathrm{Si}-\mathrm{OH}$. Over comparatively narrow ranges in bond lengths of 1.60 to $1.72 \AA$, the bond order distributions of the Si-O are very wide $(0.195-0.322)[8,41]$. Ca-OH $\ldots$ O and Si-OH . . O are the highest bond orders of HBs. The percentage contributions to total bond order of $\mathrm{HBs}, \mathrm{O}-\mathrm{H}, \mathrm{Ca}-\mathrm{O}$, and $\mathrm{Si}-\mathrm{O}$ are $1.33 \%$, $10.03 \%, 34.33 \%$, and $54.30 \%$, respectively.

By comparison, having twelve $\mathrm{OH}$ covalent bonds in the $\mathrm{Ca}-\mathrm{OH}$ form but almost no HBs, Jaffeites (c.5) have totally different bonding and structures [13,42]. All the groups of hydroxyls bonded to calcium are directed away from the chains of disilicates. In terms of bond order contribution, Jaffeites (c.5) are clearly outliers in comparison to other crystals in group (c). Among the twenty crystals considered, these have the smallest $\mathrm{Si}-\mathrm{O}$ contributions (34.1\%), thus the least total bond order distributions [39]. Suolunites (c.2) are the most conspicuous of all the group (c) crystals. In contrast to other group (c) crystals that have both Q2 and Q0, Suolunites mainly contain Q1 Si-tetrahedra. In this group, Suolunites (c.2) are the crystals that contain molecules of water and are the only naturally occurring C-S-H crystals to have $\mathrm{H}_{2} \mathrm{O}: \mathrm{Si}_{2} \mathrm{O}: \mathrm{CaO}$ ratios of 1:1:1 [8,10]. In Suolunites (c.2), all water molecules have regular covalent bond lengths of $1.00333 \AA$. The $\mathrm{H}_{2} \mathrm{O}$. . H HB is not present because these molecules of water are far apart. All the remaining HBs have comparatively strong bond orders of 0.0420 to 0.0840 and shorter bond lengths of 1.5 to $1.76 \AA$ [11]. In Suolunites (c.2), both units of $\mathrm{Q} 0$ and $\mathrm{Q} 1$ silicate types have a single $\mathrm{O}-\mathrm{H}$ covalent bond that also bonds with $\mathrm{HB}$ and the adjacent $\mathrm{O}$ of the silicate chains with a bond order of 0.0850 and a bond length of $1.543 \AA$. The remainder of the HBs originate from molecules of water to the adjacent silicate chains of oxygen. It is worth noting that $-\mathrm{O} \ldots \mathrm{H}$ has bond order values that are double those of the HB from the molecules of water [30]. Rosenhahnites (c.1) and Suolunites have the same $\mathrm{Ca} / \mathrm{Si}$ ratios but the former has no molecules of water. Therefore, the contribution of $\mathrm{HB}$ to the total bond order is minor.

The Si-O bond contributions in crystals in group (d) in the structures of the infinite silicate chains dominate the total bond order [43]. As the $\mathrm{Ca} / \mathrm{Si}$ ratios increase, the Si-O contribution to the total bond order generally reduces. Furthermore, crystal symmetry, the layer separations, and $\mathrm{H}_{2} \mathrm{O} / \mathrm{OH}$ contents also influence the contributions of the bond order. In this group, with the exceptional of Wollastonites (d.5), the C-S-H crystals are among the most hydrated. Wollastonites (d.5) are anhydrous precursor phases with $28.20 \%$ $\mathrm{Ca}-\mathrm{O}$ bonds and $71.80 \% \mathrm{Si}-\mathrm{O}$ bonds [40]. Of this group, the $\mathrm{Si}-\mathrm{O}$ bond order values portray distributions chiefly because of minor distortions from the hydroxyl ions and tetrahedral units linking the calcium and silicate chains. Two silicate chain types are reported: (1) the single silicate chains are those observed in d.8, d.7, d.5, d.4, d.3, and d.1; and (2) the double silicate chains, where two silicate chains are linked through a Bridging-O from either the interlayer sides, as in d.6 and d.2. The silicate chain presence results in high contributions of Si-O to the total bond order and layered structures of these minerals [21]. The separations of interlayers among layers vary from $4.950 \AA$ in Foshagites (d.7) to $14.00 \AA$ in $\mathrm{T} 14$ (d.3).

Regarding the mechanical anisotropies of these crystals, the layered structures created by the chains have significant effects [43]. Calcium and water molecules typically control the interlayer cohesion and reside in interlayer cavities. In Nekoites (d.1), the interlayers of separations $(7.60 \AA)$ contain all water and calcium. The Ca-O bonds in this case contribute $15.24 \%$ to the interlayer cohesions [28]. By comparison, the HB contributes $5.21 \%$ to the 
interlayer cohesions. On the contrary, in the interlayer, the T11 (d.2) has a water molecule but no calcium. Therefore, HB contributes $4.04 \%$. The HB contributes $3.17 \%$ and $5.48 \%$, and Ca-O bonds contribute $4.86 \%$ and $4.07 \%$, respectively, to the interlayer cohesions in T9 (d.4) and T14 (d.3), which have both water and calcium. In T9 (d.4) and T14 (d.3), the differences are associated with the presence of double silicates in the former and their absence in the later. Because Foshagites (d.7) and Xonotlites (d.6) have only hydroxyl ions, they unusually have low HB contributions [28]. In hydrated cements, Jennites (d.8), which have been extensively viewed as a section of the C-S-H phases in group (d), have HB contributions $(6.99 \%)$ to the interlayer cohesions.

\section{Discussion}

The investigator presented the computed electronic structures of Portlandite crystal, fifteen C-S-H crystals, and four anhydrous precursor crystals [29]. All crystals are shown by the band structures to have wide band space insulators. The bond order topologies and their contributions to the overall cohesion through the total bond order were evaluated. The researcher reported no particular rules that are universal to all crystals, but separately found certain patterns for each class [30]. The bond order, total bond order, and total bond order distributions of different crystals clearly show: (1) the accurate crystal structure importance, whose volumes determine the total bond order distribution; (2) the bond order dispersion within each type of bond in C-S-H; (3) the range of HBs; and (4) the different levels of contributions of the different types of bonds to the overall crystal cohesion. Using Ca/Si ratios, the conventional criteria for categorizing C-S-H crystals are rudimentary, as shown in the diverse views [37]. As correct quantum mechanical metrics, the investigator suggested the total bond order density/distribution (TBOD) to categorize the C-S-H crystals, which offer more in-depth insights regarding the strengths and cohesions of the materials.

Total bond order density vs. the C/S ratios, showing estimated indirect relationships, are indicated in Figure 3a. It is clear that crystals can have different total bond order density even if they have the same $C / S$ ratios. The use of total bond order density for classifications of C-S-H crystals is most relevant because the total bond order density is more relevant to cohesion and sensitive to the bonding. Moreover, these plots show that the four classes explained above do not cluster together regarding the total bond order density. Class (c) has a wider range of total bond order densities and C/S. Nevertheless, the class has narrower distributions in $\mathrm{C} / \mathrm{S}$ but a wide total bond order density range. Group (d) is thought to be closest to hydrated cements. Generally speaking, the twenty crystals can be categorized into three classes (low, medium, and high) according to their total bond order density. In particular, due to the high C/S ratios, crystals of c.5, a.1, and b.4 belong to the low total bond order density class.

By comparison, d.4, d.1, and d.2 from group (d), b.1 from group (b), and c.2 and c.1 from group (c) belong to the high total bond order density class. The remaining ten crystals, which are predominantly from class (d), belong to the medium total bond order class. Based on weak correlations of total bond order density with $C / S$ ratios and Strunz classifications, the mixing of groups symbolizes the complex tradeoffs and interplays between HBs and covalent bonds in the C-S-H structures. HBs, interlayer hydroxyls, and water drastically change the total bond order density by increasing the effective volumes without modifications to C/S ratios, even though Qn chains in crystals in group (d) tend to decrease C/S ratios. Crystal T14 (d.3), for instance, has lower C/S ratios but still had a medium total bond order density. The reason for this is that there two silicate types. Whereas d.3 has only a single silicate chain that considerably influences the total bond order density, both d.4 and d.2 arrangements have double chains of silicates. Because of different practical shortcomings, such as quick reactions with atmospheric water and synthesizing single crystals, the measured C-S-H crystals' mechanical characteristics are hard to acquire. Furthermore, as reported by Clayden et al. [44], the structures of anions in oxosilicate chains are among the constituents of the C-S-H phase by means of the nuclear magnetic resonance involving ${ }^{29} \mathrm{Si}$; this study yielded valuable information on the vicinity of silicon 
atoms. One particularly interesting aspect is the quantity of different oxosilicate anions in the sample as a function of the hydration time of the $\mathrm{C}_{3} \mathrm{~S}$ slurry. Therefore, there are only few phases of C-S-H/C-H in which the mechanical features have been experimentally obtained. For instance, the Alites (a.2) and Belite (a.1) clinker phases with a well-described stoichiometric structure are noted to have experimentally quantified Young's moduli (E) with ranges of 141-131 GPas and 148-136 GPas, respectively [33,34]. Depending on the bulk moduli value and porosities of $39.66 \mathrm{GPa}$, similar experiments found the Young's modulus for Portlandites (a.3) to range from 36-38 GPa to 34-38 GPa. As recently obtained using high pressure synchrotron X-ray diffractions, the Toberomites $14 \AA$ (d.3) crystal bulk modulus was found to be $47 \mathrm{GPa}$ [40]. The researcher found that the mean of the measured Young's moduli figures for a.3, a.1, and a.2 crystals, applying these restricted experimental values, increased as a function of the total bonds' order density and indicated a near linear fit. In addition, the measured bulk moduli also increased with total bond order density for a. 3 and d. 3 crystals. It is premature to correlate the experimental mechanical characteristics with the computed total bond order density at this stage. The researcher intends to research this further with the computed mechanical characteristics to obtain the potential patterns of mechanical characteristics with the total bond order density.

It is important to assess the multifaceted exchanges among the kinds of bonds by studying total bond order density as functions of $\mathrm{Ca}: \mathrm{Si}: \mathrm{H}$ ratios because calcium, silicon and hydrogen are the major elements of different bond types in C-S-H. Regarding $\mathrm{Ca}_{5} \mathrm{Si}_{5} \mathrm{H}$ compositions, the color-coded ternary total bond order map is shown in Figure $3 \mathrm{~b}$. The resultant contour plots provide a vibrant example of the potential sites for stages with a high total bond order density that seem to be concentrated in the area in which $\mathrm{Ca}: \mathrm{Si}: \mathrm{H}=0.25: 0.25: 0.5$. Of the twenty crystals examined, the investigator illustrated that Soulunites (c.2) with a Ca:Si ratio equal to one have the greatest total bond order density according to the criteria used. Soulunites (c.2) would be adjacent to the perfect structures and compositions. The Soulunite bonding and electronic structures have not been studied to date. The investigator has further investigated their electronic structures with the presentations of their partial densities of states (PDOS) and total density of state (DOS) resolved according to the atoms involved in diverse bonding types. In Figure $3 b$, the narrow yellow and green regions represent the medium TBOD. The lower TBOD areas are represented by the broader blue areas. It is known that countless chain structures are not present in cement hydrates (C-S-H).

On the contrary, it is broadly thought that the backbone or templates of the C-S-H disordered arrangements are designed by the mixture of Jennites (d.8) and Tobermorites (d.2-d.4) [45]. Nevertheless, the TBOD and the TO computation indicate that C-S-H arrangements in hydrated cement cannot just be surmised as C-S-H crystal mixtures or even some disordered forms of such mixtures. The following three elements are clear regarding this: (1) the variations of the bond order of comparatively weak Ca-O bonds; (2) the significant contributions of HB and its roles in influencing the bond order of all bond types; and (3) the important dispersions in the bond order of the stronger Si-O bond with smaller bond length variations [7]. Bonding information and comprehensive electronic structures are essential to interpret experimental results, particularly in spectroscopic research such as NMR, Raman, and IR measurements, because the interplays among diverse components from the structures cannot be explicitly measured by known experiments $[11,19,26]$. The implications are that attempts to apply vibrational spectroscopies for structural interpretations, such as Raman and IR, have to be explored cautiously with special focus paid to small nuances and features, such as asymmetry and peak widths.

The researcher noted that silicate with a stronger covalent bond is anticipated to contribute greatly to the overall crystal stiffness under small deformations from the perspective of mechanical characteristics [45]. Nevertheless, hydrated crystals with a lower degree of polymerization can make substantial contributions to the stiffness of materials in the HB networks via HBs. On crystals with finite silicate chains, the bond order analyses show that $\mathrm{HB}, \mathrm{H}_{2} \mathrm{O}$, and $\mathrm{OH}$ networks all play major roles in the crystal cohesion. The 
Si-O covalent bond is more significantly not likely to be the major crystal strength source as usually illustrated in the literature [15]. The failures and the fracture behaviors and mechanical response nonlinearity are usually controlled by the weak hydrogen or ionic bonds in multi-component crystals that include hydrogen, ionic, and covalent bonds. Diverse atomic-scale distortion mechanisms are prompted by and persevere under diverse loading paths in the complicated material systems. The bond orders and different bond types, and the silicate polymerization, will affect the deformation mechanisms for the more disordered C-S-H and C-S-H crystals. Along the silicate chains supplemented by planes of weaknesses, highly polymerized structures such as Jennites and Tobermorites in this regard are likely to have highly anisotropic mechanical responses with stiff responses [15]. Suolunites, which have the lowest polymerization degrees of silicates, highest total bond order density, and high contributions of HBs, are likely to have an absence of weak planes and comparably high stiffness.

\section{Conclusions}

In conclusion, the researcher presented convincing arguments for utilizing quantum mechanical metrics, the total bond orders, and total bond order distributions as the most vital criteria for assessing the crystalline cohesions in C-S-H crystals. These metrics encompass the effects of both interatomic interactions and geometric elements. Thus, the total bond order distribution and bond order offer comprehensive and in-depth measures for the overall behaviors of these diverse groups of materials. The total bond order distributions must clearly be substituted for the conventional and longstanding $\mathrm{Ca} / \mathrm{Si}$ ratios applied in categorizing the cement substances. The inconspicuous Suolunite crystals were found to have the greatest total bond order distributions and the perfect bonding characteristics, compositions, and structures for cement hydrates. These findings should serve as motivations for cement technologists involved in hydraulic cement molecular-scale engineering. The syntheses of hydration paths or anhydrous materials resulting in hydration products of Suolunite types may generate strong building materials. Moreover, these research results make it very clear that an understanding of the inter-atomic bonding features and electronic structures is necessary for developments of practical structural instruments of disordered cement hydrates and experimental spectroscopic data interpretations. In this research, the approaches utilized can be applied to wide classes of complex material systems that integrate hydrogen, covalent, and ionic bonds, such as classes of the apatite minerals appropriate to biological systems.

Supplementary Materials: The following are available online at https:/ / static-content.springer.com/ esm/art\%3A10.1038\%2Fsrep07332/MediaObjects/41598_2014_BFsrep07332_MOESM1_ESM.pdf. Table S1. Experimental crystal parameters of the 20 crystals.

Funding: This research received no external funding.

Institutional Review Board Statement: Not applicable.

Informed Consent Statement: Not applicable.

Data Availability Statement: The data presented in this study are available on request from the corresponding author.

Conflicts of Interest: The author declares no conflict of interest.

\section{References}

1. Dharmawardhana, C.C.; Misra, A.; Ching, W.-Y. Quantum Mechanical Metric for Internal Cohesion in Cement Crystals. Sci. Rep. 2014, 4, 7332. [CrossRef] [PubMed]

2. Cho, B.H.; Chung, W.; Nam, B.H. Molecular Dynamics Simulation of Calcium-Silicate-Hydrate for Nano-Engineered Cement Composites-A Review. Nanomaterials 2020, 10, 2158. [CrossRef] [PubMed]

3. Scrivener, K.L.; Kirkpatrick, R.J. Innovation in use and research on cementitious material. Cem. Concr. Res. 2008, 38, $128-136$. [CrossRef] 
4. Honorio, T. Monte Carlo Molecular Modeling of Temperature and Pressure Effects on the Interactions between Crystalline Calcium Silicate Hydrate Layers. Langmuir 2019, 35, 3907-3916. [CrossRef]

5. Geng, G.; Myers, R.J.; Qomi, M.J.A.; Monteiro, P.J.M. Densification of the Interlayer Spacing Governs the Nanomechanical Properties of Calcium-Silicate-Hydrate. Sci. Rep. 2017, 7, 10986. [CrossRef] [PubMed]

6. Nonat, A. The Structure and Stoichiometry of C-S-H. Cem. Concr. Res. 2004, 34, 1521-1528. [CrossRef]

7. Dharmawardhana, C.; Bakare, M.; Misra, A.; Ching, W.-Y. Nature of Interatomic Bonding in Controlling the Mechanical Properties of Calcium Silicate Hydrates. J. Am. Ceram. Soc. 2016, 99, 2120-2130. [CrossRef]

8. Bonnaud, P.A.; Ji, Q.; Coasne, B.; Pellenq, R.J.-M.; Van Vliet, K.J. Thermodynamics of Water Confined in Porous Calcium-SilicateHydrates. Langmuir 2012, 28, 11422-11432. [CrossRef]

9. Qomi, M.J.A.; Bauchy, M.; Pellenq, R.J.-M. Nanoscale Composition-Texture-Property Relation in Calcium-Silicate-Hydrates. In Handbook of Materials Modeling; Springer International Publishing: Cham, Switzerland, 2020; pp. 1761-1792. [CrossRef]

10. Zhou, Y.; Zheng, H.; Qiu, Y.; Zou, X.; Huang, J. A Molecular Dynamics Study on the Structure, Interfaces, Mechanical Properties, and Mechanisms of a Calcium Silicate Hydrate/2D-Silica Nanocomposite. Front. Mater. 2020, 7, 127. [CrossRef]

11. Murray, S.J. Determination of Strength and Stiffness of Calcium Silicate Hydrate Using Molecular Dynamics; Proquest, Umi Dissertation Publishing: Ann Arbor, MI, USA, 2011.

12. Fonseca, P.C. Characterization and Numerical Modeling of Calcium Silicate Hydrate; Proquest, Umi Dissertation Publishing: Ann Arbor, MI, USA, 2011.

13. Richardson, I.G. The Calcium Silicate Hydrates. Cem. Concr. Res. 2008, 38, 137-158. [CrossRef]

14. Hou, D.; Li, H.; Zhang, L.; Zhang, J. Nano-Scale Mechanical Properties Investigation of C-S-H from Hydrated Tri-Calcium Silicate by Nano-Indentation and Molecular Dynamics Simulation. Constr. Build. Mater. 2018, 189, 265-275. [CrossRef]

15. Hu, P.; Dai, W. Study on Molecular Dynamics Simulation of Calcium Silicate Hydrate (C-S-H) Gels. In Communications in Computer and Information Science; Springer: Berlin/Heidelberg, Germany, 2011; pp. 142-147. [CrossRef]

16. Cuesta, A.; Zea-Garcia, J.D.; Londono-Zuluaga, D.; De la Torre, A.G.; Santacruz, I.; Vallcorba, O.; Dapiaggi, M.; Sanfélix, S.G.; Aranda, M.A.G. Multiscale Understanding of Tricalcium Silicate Hydration Reactions. Sci. Rep. 2018, 8, 1-11. [CrossRef] [PubMed]

17. Taylor, H.F.W.; Roy, D.M. In Proceedings of the Structure and Composition of Hydrates at 7th International Congress on the Chemistry of Cement: Principal Reports, Paris, France, Editions Septima, PII 2/1-13 (1980). Available online: https:/ /www.iccc-online.org/ fileadmin/gruppen/iccc/proceedings/ICCC7_1980.pdf (accessed on 18 October 2021).

18. Strunz, H. Mineralogische Tabellen, 8th ed.; Akad. Verl.-Ges. Geest u. Portig: Leipzig, Germany, $1982 ;$ pp. 1-621.

19. Youssef, M. Probing Water Properties and Cationic Exchange in Calcium-Silicate-Hydrate: An Atomistic Modeling Study; Massachusetts Institute of Technology Dissertation Publishing: Boston, MA, USA, 2010.

20. Hou, D. Molecular Simulation on Cement-Based Materials: From Theory to Application; Springer: Singapore, 2020. [CrossRef]

21. Dharmawardhana, C.C.; Misra, A.; Ching, W.-Y. Theoretical Investigation of C-(A)-S-H(I) Cement Hydrates. Constr. Build. Mater. 2018, 184, 536-548. [CrossRef]

22. Abdolhosseini Qomi, M.J.; Ulm, F.-J.; Pellenq, R.J.-M. Evidence on the Dual Nature of Aluminum in the Calcium-Silicate-Hydrates Based on Atomistic Simulations. J. Am. Ceram. Soc. 2012, 95, 1128-1137. [CrossRef]

23. Tu, Y.; Yu, Q.; Wen, R.; Shi, P.; Yuan, L.; Ji, Y.; Sas, G.; Elfgren, L. Molecular Dynamics Simulation of Coupled Water and Ion Adsorption in the Nano-Pores of a Realistic Calcium-Silicate-Hydrate Gel. Constr. Build. Mater. 2021, 299, 123961. [CrossRef]

24. Geng, G.; Vasin, R.N.; Li, J.; Qomi, M.J.A.; Yan, J.; Wenk, H.-R.; Monteiro, P.J.M. Preferred Orientation of Calcium Aluminosilicate Hydrate Induced by Confined Compression. Cem. Concr. Res. 2018, 113, 186-196. [CrossRef]

25. Pan, T.; Xia, K.; Wang, L. Chloride Binding to Calcium Silicate Hydrates (C-S-H) in Cement Paste: A Molecular Dynamics Analysis. Int. J. Pavement Eng. 2010, 11, 367-379. [CrossRef]

26. Zhang, L.; Lin, Z.; Li, Z. The Structure of Silicate Ions in C-S-H Discussed from Chemical Composition. Adv. Cem. Res. 2012, 24, 263-281. [CrossRef]

27. Dharmawardhana, C.C.; Misra, A.; Aryal, S.; Rulis, P.; Ching, W.Y. Role of Interatomic Bonding in the Mechanical Anisotropy and Interlayer Cohesion of CSH Crystals. Cem. Concr. Res. 2013, 52, 123-130. [CrossRef]

28. Jin, S.; Li, J.; Xu, W.; Ding, Q. Heterogeneous Nature of Calcium Silicate Hydrate (C-S-H) Gel: A Molecular Dynamics Study. J. Wuhan Univ. Technol. (Mater. Sci. Ed.) 2020, 35, 435-440. [CrossRef]

29. Brunet, F.; Bertani, P.; Charpentier, T.; Nonat, A.; Virlet, J. Application of ${ }^{29}$ Si Homonuclear and $1 \mathrm{H}-29 \mathrm{Si}$ Heteronuclear NMR Correlation to Structural Studies of Calcium Silicate Hydrates. J. Phys. Chem. B 2004, 108, 15494-15502. [CrossRef]

30. Manzano, H.; Masoero, E.; Lopez-Arbeloa, I.; Jennings, H.M. Shear Deformations in Calcium Silicate Hydrates. Soft Matter 2013, 9, 7333. [CrossRef]

31. Lothenbach, B.; Nonat, A. Calcium Silicate Hydrates: Solid and Liquid Phase Composition. Cem. Concr. Res. 2015, 78, 57-70. [CrossRef]

32. Özçelik, V.O.; Garg, N.; White, C.E. Symmetry-Induced Stability in Alkali-Doped Calcium Silicate Hydrate. J. Phys. Chem. C Nanomater. Interfaces 2019, 123, 14081-14088. [CrossRef]

33. Masoumi, S.; Zare, S.; Valipour, H.; Abdolhosseini Qomi, M.J. Effective Interactions between Calcium-Silicate-Hydrate Nanolayers. J. Phys. Chem. C Nanomater. Interfaces 2019, 123, 4755-4766. [CrossRef] 
34. Hou, D.; Zhao, T.; Ma, H.; Li, Z. Reactive Molecular Simulation on Water Confined in the Nanopores of the Calcium Silicate Hydrate Gel: Structure, Reactivity, and Mechanical Properties. J. Phys. Chem. C Nanomater. Interfaces 2015, 119, 1346-1358. [CrossRef]

35. Hou, D.; Zhang, J.; Li, Z.; Zhu, Y. Uniaxial Tension Study of Calcium Silicate Hydrate (C-S-H): Structure, Dynamics and Mechanical Properties. Mater. Struct. 2015, 48, 3811-3824. [CrossRef]

36. Özçelik, V.O.; White, C.E. Nanoscale Charge-Balancing Mechanism in Alkali-Substituted Calcium-Silicate-Hydrate Gels. J. Phys. Chem. Lett. 2016, 7, 5266-5272. [CrossRef]

37. Delhorme, M.; Labbez, C.; Turesson, M.; Lesniewska, E.; Woodward, C.E.; Jönsson, B. Aggregation of Calcium Silicate Hydrate Nanoplatelets. Langmuir 2016, 32, 2058-2066. [CrossRef]

38. Hou, D.; Zhao, T.; Wang, P.; Li, Z.; Zhang, J. Molecular Dynamics Study on the Mode I Fracture of Calcium Silicate Hydrate under Tensile Loading. Eng. Fract. Mech. 2014, 131, 557-569. [CrossRef]

39. Richardson, I.G. The Nature of C-S-H in Hardened Cements. Cem. Concr. Res. 1999, 29, 1131-1147. [CrossRef]

40. Li, B.; Li, N.; Brouwers, H.J.H.; Yu, Q.; Chen, W. Understanding Hydrogen Bonding in Calcium Silicate Hydrate Combining Solid-State NMR and First Principle Calculations. Constr. Build. Mater. 2020, 233, 117347. [CrossRef]

41. Alkhateb, H.; Al-Ostaz, A.; Cheng, A.H.-D.; Li, X. Materials Genome for Graphene-Cement Nanocomposites. J. Nanomech. Micromech. 2013, 3, 67-77. [CrossRef]

42. Richardson, I.G.; Skibsted, J.; Black, L.; Kirkpatrick, R.J. Characterisation of Cement Hydrate Phases by TEM, NMR and Raman Spectroscopy. Adv. Cem. Res. 2010, 22, 233-248. [CrossRef]

43. Jamil, T.; Javadi, A.; Heinz, H. Mechanism of Molecular Interaction of Acrylate-Polyethylene Glycol Acrylate Copolymers with Calcium Silicate Hydrate Surfaces. Green Chem. 2020, 22, 1577-1593. [CrossRef]

44. Clayden, N.J.; Dobson, C.M.; Groves, G.W.; Rodger, S.A. The application of solid state nuclear magnetic resonance spectroscopy techniques to the study of the hydration of tricalcium silicate. In Proceedings of the 8th ICCC, t. III, Rio de Janeiro, Brazil, June 1986; p. 51.

45. Zhou, Y.; Hou, D.; Geng, G.; Feng, P.; Yu, J.; Jiang, J. Insights into the Interfacial Strengthening Mechanisms of Calcium-SilicateHydrate/Polymer Nanocomposites. Phys. Chem. Chem. Phys. 2018, 20, 8247-8266. [CrossRef] [PubMed] 